\title{
O que há de novo na formação de professores para a Educação Especial?
}

Maria Helena Michels*

\section{Resumo}

$\mathrm{Na}$ esteira de conferências internacionais, as políticas educacionais brasileiras vêm se apoiando em discursos inclusivos. A formação de professores para a educação especial tem sido considerada ponto fulcral para dar sustentabilidade a este discurso. Buscando contribuir com tal discussão, o presente artigo propõe reflexões acerca da política de formação inicial e continuada. Por intermédio de algumas pesquisas desenvolvidas, vimos percebendo que a centralidade na formação de professores para a educação especial está no professor do atendimento educacional especializado (AEE), que apresenta, como ponto central de formação, as técnicas e recursos especializados. Mesmo aquelas ações referentes à articulação com a classe comum estão atreladas ao repasse desses recursos e técnicas, e não à discussão pedagógica. Além disso, a proposição atual de formação de professores não rompe com o modelo de formação tradicionalmente destinado à área. Com tais elementos, podemos considerar que a formação de professores que trabalham com alunos considerados com deficiência está centrada na formação continuada. Tanto essa como a formação inicial não têm como foco central a articulação entre o AEE e a classe comum. Há, ainda, uma preponderância nas formações de um modelo que secundariza o pedagógico e privilegia o médico-psicológico. Em síntese, essa proposição de formação pode sinalizar que a proposta de inclusão em curso no País não pressupõe a apropriação do conhecimento escolar por parte dos alunos com deficiência.

Palavras-chave: Políticas de inclusão. Formação de professores. Atendimento educacional especializado.

\section{What is new in training Special Education teachers?}

\section{Abstract}

Conveying along international conferences, the Brazilian educational policies have been basing themselves on the inclusive speech. To provide such with sustainability the training of special education teachers. Pursuing to contribute with that discussion, the present paper proposes reflections about initial and continuous training. Through some research that has been developed, we perceived that the core of teacher training for special education lies on the teachers of Specialized Complementary Educational Service (AEE, atendimento educa-

\footnotetext{
* Professora da Universidade Federal de Santa Catarina, Departamento de Estudos Especializados em Educação. Atua na área de Educação Especial, Florianópolis, Santa Catarina, Brasil.
} 
cional especializado). This service features specialized techniques and resources as a central point in the training. Even those actions that make reference to the relationship with the common class are linked to the transfer of those resources and techniques, not to the pedagogical discussion. Moreover, the current teacher training proposition does not break with the training model traditionally specified for that area. Such elements may lead us to consider that the training of teachers who work with students considered to be disabled is not centered in continuous training. Both that and the initial training do not feature the relationship between $\mathrm{AEE}$ and the common class as their central focus. Furthermore, on training there is a preponderance of a model that places the pedagogical in second place, in favor of the medical-psychological aspect. In summary, this proposition of training may signal that the proposal for inclusion in course in the country does not presuppose the acquisition of school knowledge by students with disabilities.

Keywords: Inclusion policies. Teacher training. Specialized complementary educational service.

Com este texto, pretendemos colaborar com a discussão sobre a política de formação de professores no Brasil, especificamente àquela voltada à Educação Especial.

Em análises referentes à política de educação inclusiva no Brasil, autores como Garcia (2008) e Bueno (2008) observam as influências dos organismos internacionais na formulação e encaminhamentos de proposições voltadas à organização das práticas pedagógicas que dizem respeito à educação de alunos com deficiência. As redes de ensino têm sido interpeladas a executarem as políticas em questão, de maneira que cada esfera administrativa vem se apropriando da política de inclusão ao seu modo. A formação dos professores que trabalham com os alunos com deficiência, nas diferentes esferas administrativas, é expressão de tal assimilação e é foco de nossas análises nesse texto.

Para discutir como esta formação vem ocorrendo, vamos apresentar dados referentes a duas pesquisas que envolveram municípios do Estado de Santa Catarina. Tais investigações, apesar de não terem como foco central a formação de professores, possibilitaram algumas reflexões sobre o tema.

Para que possamos discutir formação de professores para a Educação Especial, neste momento histórico, é salutar considerar a apreensão da política de inclusão no estado brasileiro, bem como a proposição de formação de professores para a Educação Básica. Compreende-se que a especificidade dessa formação esteja eivada de elementos presentes na formação dos professores para a Educação Básica. 


\section{A inclusão vista como par dialético da exclusão}

Nos últimos anos, no Brasil, observa-se a apropriação do discurso internacional relacionado à inclusão promulgando a universalização da Educação Básica nos países em desenvolvimento. Ganham destaque discussões sobre alguns temas, como: flexibilização curricular, preparação da escola regular para receber os alunos considerados com deficiência, técnicas e recursos que auxiliam nessa ação e formação de professores como elementos indispensáveis para o sucesso dessa política.

Alguns autores (CORREIA, 2004; FRIGOTTO, 2009; LEHER,2009) mostram, em seus estudos, que a política de inclusão não diz respeito unicamente ao ingresso dos alunos considerados com deficiência no ensino regular. Para Correia (2004), tal discurso se constitui em uma narrativa que, ao ser incorporada pelo campo educacional, pode ser considerada como "ideologia da inclusão". Leher (2009) aponta para a compreensão de que inclusão (assim como exclusão) é uma das categorias fundamentais para manter a ordem social atual. Nessa mesma lógica, Frigotto (2009, p. 69) indica que a noção de inclusão "[...] obscurece o que produz a crise mais profunda e universal do sistema capitalista: a hipertrofia do capital especulativo, o desemprego estrutural e a precarização crescente das condições de trabalho".

Considerando que inclusão está, necessariamente, articulada à exclusão Castel (2000) e Correia (2004) advertem que esta última vem sendo utilizada para definir todas as mazelas do mundo. Para Correia (2004, p. 1).

[...] a noção de exclusão social tornou-se numa espécie de 'lugar comum' que designa um conjunto heterogéneo de fenómenos sem os discriminar numa lógica em que a simples designação do fenómeno parece fazer a economia da sua explicação e da justificação das modalidades de intervenção social desenvolvidas.

Para Leher (2009, p. 230), o termo mais adequado para nos referirmos ao processo atualmente denominado de exclusão é expropriação:

[...] se historicamente é inapropriado qualificar a sorte dos trabalhadores como exclusão e inclusão, é forçoso reconhecer que essas expressões rapidamente se difundiram no léxico dos organismos internacionais, dos governos, dos estudos acadêmicos e no pensamento político de direita e de esquerda.

No caso da educação escolar, a situação não é diferente, uma vez que é considerada, historicamente, um agente privilegiado para a correção das desigualdades sociais geradas pelo sistema capitalista. Por intermédio de suas ações é que se busca a "inclusão" dos sujeitos excluídos dos processos soci- 
ais mais amplos. Freitas et al. (2004, p. 63) advertem que a exclusão social tem se mostrado cada vez mais sofisticada:

Quanto mais parece que o direito de possuir é dado a todos, mais se ensina o dever de consumir e de aprender a consumir/desejar a partir do lugar social que se ocupa. Assim, ao direito de acesso à educação (inclusão em todos os níveis de ensino) contrapõe-se o dever de aceitar uma determinada concepção de qualidade de ensino, que oculta seus beneficiários e que fabrica triIhas diferenciadas e meritocráticas de sucesso e fracasso. (exclusão por dentro)

Não obstante, a educação dos sujeitos com deficiência pode ser tomada como expressão dessa discussão. A partir de algumas análises sobre a produção na área de Educação Especial, Michels (2004) observou que a inclusão de alunos considerados com deficiência pode ser tratada como um problema restrito das competências dos professores. A inclusão, neste caso, é o objetivo primeiro e último desse processo. Desta maneira, a inclusão prescinde da aprendizagem. Tais produções foram denominadas pela autora como perspectiva "propositiva", na qual se percebe a ausência de análise sobre as relações sociais concretas que expliquem as relações sociais presentes no processo de inclusão/exclusão. O professor é considerado o responsável pelo sucesso ou fracasso dos "encaminhamentos" inclusivistas. Outras produções na área se contrapõem a essa perspectiva e encontram-se nelas a compreensão de que a história (da sociedade, da Educação e da Educação Especial) é a base para desenvolver um exame cuidadoso da realidade educacional desses alunos. A materialidade das condições históricas e sociais para a inclusão é que possibilita a discussão sobre ela. Os alunos e professores são tidos como sujeitos, constituintes do processo, e não vítimas de decisões do "sistema". Consolidando o tratamento diferente para as desigualdades produzidas pela própria sociedade capitalista, a perspectiva denominada por Michels (2004) como "analítica" trata a inclusão como um processo perverso, uma vez que celebra a diferença que exclui.

Contudo, é importante compreendermos que,

[...] é no bojo desse pensamento positivista, de encaminhamento tecnicista e organicista, que nasce outra maneira de entender a relação entre a sociedade e a deficiência. É, justamente, da sua negação que emerge a compreensão de que é necessário pensar o fenômeno da deficiência nas relações produzidas por esta sociedade. É dessa relação que surge a compreensão de que fizemos parte dessa organização, reafirmando-a ou negando-a. (MICHELS, 2004, p. 35)

A reforma educacional, iniciada nos anos 1990, distancia-se da perspectiva "analítica" e traz, em sua essência, a exclusão social como processo 
natural. Porém, agora, esta exclusão abandona a forma objetiva (vista na educação por meio da evasão e repetência, principalmente) e configura-se na exclusão subjetiva (FREITAS, 2002). Esta última apresenta-se de maneira mais perversa que a primeira, pois deposita no próprio excluído a responsabilidade de sua condição.

Se a política de inclusão no Brasil pode ser considerada como de perspectiva teórica propositiva, podemos questionar como, de dentro de tal proposta, vem sendo indicada a formação de professores para atender aos alunos considerados com deficiência? Qual a relação dessa formação com processos de exclusão/inclusão educacional dos alunos da Educação Especial?

\section{A formação de professoares e a política de inclusão: um novo profes- sor?}

Desde 1994, quando ocorreu, na Espanha, a Conferência Mundial sobre Necessidades Educativas Especiais: acesso e qualidade e foi aprovada a "Declaração de Salamanca de Princípios, Políticas e Práticas das Necessidades Educativas Especiais e uma Linha de Ação" (UNESCO, 1994), a formação de professores compõe a estrutura de ação para a inclusão.

Especificamente no Brasil, com a aprovação da LDBEN n. 9394/96, observa-se um aumento dos números de matrículas de alunos considerados com deficiência em escolas públicas. ${ }^{1}$

Naquele momento, a formação de professores para atender alunos com deficiência ganha destaque e, em 2001, o CNE aprova a Resolução 02/ 2001, que, ao reiterar a LDBEN, apresenta dois tipos distintos de professores para trabalharem com alunos "portadores de necessidades educacionais especiais": os capacitados e os especializados.

Essa Resolução define como professores "capacitados" aqueles que atuam em classes comuns com alunos que apresentam necessidades educacionais especiais e que comprovem que, em sua formação, de nível médio ou superior, foram incluídos conteúdos sobre educação especial (BRASIL, 2001). Já os professores especializados em Educação Especial são considerados aqueles formados em cursos de licenciatura em Educação Especial ou em uma de suas áreas. O professor especializado também poderá ser formado em cursos de complementação de estudos ou pós-graduação em áreas específicas da Educação Especial, posterior à licenciatura (BRASIL, 2001).

Especificamente em relação à formação inicial, em 2006, foi aprovada a Resolução n. 1 do Conselho Nacional de Educação, que Institui as Diretrizes Curriculares Nacionais para o Curso de Graduação em Pedagogia, o qual resultou de disputas entre projetos distintos. ${ }^{2}$

A Resolução CNE 1/2006, segundo Saviani (2007, p. 127), apresentase de maneira paradoxal: 
[...] ao mesmo tempo, extremamente restritas e demasiadamente extensivas: muito restritas no essencial e assaz excessivas no acessório. São restritas no que se refere ao essencial, isto é, àquilo que configura a pedagogia como um campo teórico-prático dotado de um acúmulo de conhecimentos e experiências resultantes de séculos de história. Mas são extensivos no acessório, isto é, se dilatam em múltiplas e reiterativas referências à linguagem hoje em evidência.

Ao docente caberia, então, a atuação em várias áreas, em inúmeros espaços e com diversificação de tarefas.

Evangelista (2008, p. 1-2), ao analisar as Diretrizes para a Pedagogia, levanta a hipótese segundo a qual:

Está em construção um profissional polivalente, com um espectro de atuação amplo, embora com formação restrita do ponto de vista teórico. O alargamento da formação e da ação docente sugere um processo de reconversão que faz suceder ao Pedagogo o Licenciado em pedagogia, docente que atuará na docência em sentido amplo, na gestão e na pesquisa.

A tese da reconversão docente assenta-se na "lógica" de que se o que se quer é formar uma "nova" mentalidade, para uma "nova" sociedade, onde os trabalhadores sejam mais flexíveis e adaptáveis a situações de mercado, o professor é elemento importante e este deve ser reconvertido, ou seja, ter sua própria função adaptada as atuais condições e necessidades. afirma que

Compartilharmos da ideias de Cartolano (1998, p. 29) quando esta

Não podemos pensar isoladamente a formação do professor de educação especial. Ao contrário, é preciso considerá-la como parte integrante da formação dos profissionais da educação em geral e submetê-la, portanto, às mesmas discussões que se vêm fazendo neste âmbito, seja no âmbito nacional, estadual ou regional.

Desta maneira, podemos questionar se é possível pensar na tese da reconversão do trabalho docente quando nos detemos na análise da proposição da formação de professores de Educação Especial.

Com a aprovação da Resolução CNE 1/2006 (BRASIL, 2006), que extingue as habilitações dos Cursos de Pedagogia, inclusive aquelas responsáveis pela formação dos professores para atenderem os alunos considerados com deficiência, a formação desses professores especialistas é indicada para que ocorra em nível de pós-graduação. ${ }^{3}$ 
Além desses pontos, a Resolução 2/2001 indica que tal formação pode ocorrer com a chamada formação continuada, para os professores que já estejam atuando. Neste caso, não há especificação de carga horária.

Na Política Nacional de Educação Especial na Perspectiva da Educação Inclusiva (BRASIL, 2008), a formação dos professores pode se dar por intermédio da formação continuada. Não há qualquer indicativo de necessidade da formação dos professores regentes de classe que possuem em suas salas alunos considerados com deficiência:

\begin{abstract}
Para atuar na educação especial, o professor deve ter como base da sua formação, inicial e continuada, conhecimentos gerais para o exercício da docência e conhecimentos específicos da área. Essa formação possibilita a sua atuação no atendimento educacional especializado e deve aprofundar o caráter interativo e interdisciplinar da atuação nas salas comuns do ensino regular, nas salas de recursos, nos centros de atendimento educacional especializado, nos núcleos de acessibilidade das instituições de educação superior, nas classes hospitalares e nos ambientes domiciliares, para a oferta dos serviços e recursos de educação especial. (BRASIL, 2008, p. 17-18)
\end{abstract}

Borowsky (2010) analisou uma proposta de formação de professores para a Educação Especial oferecida pelo Programa "Educação Inclusiva: direito a diversidade, qual seja, o Curso de Aperfeiçoamento de professores para o Atendimento Educacional Especializado. A autora observou, pela análise documental, que esta proposta de formação de professores, que tem grande alcance nacional,

[...] não apresenta uma base teórica única, mas apóiase em diversas teorias. Tais teorias são utilizadas indiscriminadamente. Intelectuais de correntes de pensamento diferentes, muitas delas antagônicas, são apresentados sem que se considere sua filiação teórica ou os pressupostos ideológicos presentes em suas produções. Isso denota um ecletismo teórico presente nos documentos.

Tal ecletismo parece-nos não ocorrer ao acaso. Podemos entender que quando os documentos utilizamse de diversas teorias, buscam amenizar os possíveis conflitos decorrentes das apropriações deste material. Visam gerar maior número possível de aceitação por parte dos professores que serão formados por esta proposta. (BOROWSKY, 2010, p. 123)

Durante sua pesquisa, a citada autora observa a permanência do modelo médico-pedagógico e psicopedagógico como base da formação continuada de professores de Educação Especial. Tal base também está presente na formação inicial de professores, como observado por Michels (2004). 
Com as Diretrizes Operacionais para o Atendimento Educacional Especializado na Educação Básica, modalidade Educação Especial (BRASIL, 2009), ${ }^{4}$ em seu art. 12, se institui que "Para atuação no AEE [Atendimento Educacional Especializado], o professor deve ter formação inicial que o habilite para o exercício da docência e formação específica para a Educação Especial." Porém, em qual curso seria oferecida tal formação? Estaríamos aqui propondo uma formação em nível de pós-graduação? Ou a proposta seria a formação em curso de graduação que não a histórica formação em pedagogia? Nestes dois casos não estaríamos novamente distanciando a formação de professores para atender os alunos da Educação Especial da formação do professor da classe comum?

Ainda nesta Resolução, em seu art. 13, encontramos as atribuições do professor do Atendimento Educacional Especializado que são:

I - identificar, elaborar, produzir e organizar serviços, recursos pedagógicos, de acessibilidade e estratégias considerando as necessidades específicas dos alunos público-alvo da Educação Especial; II - elaborar e executar plano de Atendimento Educacional Especializado, avaliando a funcionalidade e a aplicabilidade dos recursos pedagógicos e de acessibilidade; III - organizar o tipo e o número de atendimentos aos alunos na sala de recursos multifuncionais; IV - acompanhar a funcionalidade e a aplicabilidade dos recursos pedagógicos e de acessibilidade na sala de aula comum do ensino regular, bem como em outros ambientes da escola; $V$ - estabelecer parcerias com as áreas intersetoriais na elaboração de estratégias e na disponibilização de recursos de acessibilidade; VI - orientar professores e famílias sobre os recursos pedagógicos e de acessibilidade utilizados pelo aluno; VII - ensinar e usar a tecnologia assistiva de forma a ampliar habilidades funcionais dos alunos, promovendo autonomia e participação; VIII - estabelecer articulação com os professores da sala de aula comum, visando à disponibilização dos serviços, dos recursos pedagógicos e de acessibilidade e das estratégias que promovem a participação dos alunos nas atividades escolares. (BRASIL, 2009)

Percebe-se que a centralidade das ações dos professores do atendimento educacional especializado (AEE) permanece nas técnicas e nos recursos especializados presentes em todos os pontos da citada Resolução. Mesmo aquelas ações que dizem respeito à articulação com a classe comum não estão atreladas à discussão pedagógica, e sim à utilização de recursos específicos. Tal centralidade pode estar relacionada à perspectiva psicopedagógica, em sua versão comportamental, que indica a necessidade de técnicas centradas na deficiência dos alunos e recursos diretamente vinculados a cada tipologia de deficiência. 
Essa breve reflexão possibilita percebermos que, com a LDBEN 9.394/ 96, a Resolução 02/2001, as Diretrizes (BRASIL, 2006), a Política Nacional de Educação Especial na Perspectiva da Educação Inclusiva (BRASIL, 2008) e a Resolução n. 4 (2009) as ambiguidades que historicamente estão presentes na formação dos professores persistem. ${ }^{5}$

Além de manter ambiguidades a proposição atual de formação de professores não rompe com o modelo de formação tradicionalmente destinado à área. Com os resultados da pesquisa desenvolvida em municípios catarinenses, podemos compreender que a área de Educação Especial, que tem se organizado tendo por base o modelo médico-pedagógico, chega a ser confundida com este modelo. Esse organiza o currículo do curso de formação de seus professores, indica o trabalho a ser desenvolvido com os alunos considerados com deficiência, influencia as políticas públicas voltadas à Educação Especial, entre outras ações que envolvem a área.

O modelo médico-pedagógico recebe críticas que não são facilmente aceitas pela área, uma vez que o mesmo compõe o pensamento hegemônico, não somente na Educação Especial, mas na educação de maneira geral, que tem a base biológica como explicação para o insucesso escolar. ${ }^{6}$ Agrega-se a esta perspectiva de base biológica a sustentação psicológica de que o fracasso escolar decorre de questões individuais, e não sociais.

As reflexões apresentadas até aqui possibilitam questionar: se a proposta de formação desses professores para a Educação Especial tem como máxima a inclusão, o modelo médico-psicológico auxilia este processo? A formação de professores proposta hoje, pela política educacional brasileira, possibilita a superação da exclusão educacional? Ou poderíamos afirmar que tal proposição consolida a exclusão dos alunos das classes populares, sendo eles considerados com deficiência ou não, no seio da escola?

\section{A formação de professores para a Educação Especial em Santa Catarina: algumas considerações}

Em pesquisa realizada durante os anos de 2006 e 2008, que contou com a participação de sete municípios catarinenses, foram obtidos dados sistematizados em documentos elaborados pelos representantes dos governos municipais e mediante entrevistas realizadas com as coordenadoras da Educação Especial de cada município. Tais dados foram analisados tomando como referência os eixos trabalho pedagógico e formação docente.

Em relação especificamente àformação de professores, os dados obtidos permitiram pensar na existência de um paradoxo, qual seja: a formação docente numa perspectiva clínica como sustentação para o trabalho escolar com sujeitos com necessidades especiais, que deve ter como objetivo desenvolver processos de escolaridade. A elaboração de tal paradoxo está pautada na 
análise de encaminhamentos políticos mais amplos, já apresentados aqui, e pela reflexão dos dados obtidos nos municípios pesquisados.

Considerando que as proposições políticas não são apreendidas passivamente pelas redes de ensino e seus professores e professoras, mas que se constituem em processos de "contestação", conforme as condições objetivas e subjetivas para tal (OZGA, 2000) é que optamos por analisar os dados referentes à formação de professores nos municípios pesquisados, objetivando perceber as similaridades e diferenças destes encaminhamentos e as continuidades e rupturas com a política denominada de inclusiva.

No que concerne à formação inicial dos profissionais responsáveis pela organização da Educação Especial, observamos que é, majoritariamente, a graduação em Pedagogia. ${ }^{7}$ Em quatro municípios, os coordenadores do setor haviam cursado pós-graduação em nível de especialização - principalmente em psicopedagogia - e em dois dos municípios esta função era ocupada por pessoas com título de mestre em educação.

Dos profissionais que desenvolviam atividades nos serviços especializados oferecidos pelas redes de ensino, todos cursaram Pedagogia, mas poucos com habilitação específica em Educação Especial. É curioso notar que, quando das entrevistas, a maioria dos coordenadores do setor indicou que a formação inicial dos professores que atuam em sala de aula regular com alunos com diagnóstico de deficiência não é fundamental para o desenvolvimento desses trabalhos. Houve a indicação de que a formação em serviço e a prévia disponibilidade em trabalhar com estes alunos (sensibilidade, abertura para a diversidade, experiência com crianças deficientes, entre outros) seriam os principais requisitos para o desenvolvimento de um bom trabalho.

Tais dados recolocam o debate presente nos cursos de Pedagogia que se refere à centralidade ou não na docência. Algumas discussões indicam que o Curso de Pedagogia não tem se esmerado na formação docente. Os dados indicam que esta formação não é considerada tão importante, pois não seria esta nem os cursos de especialização a base para o desenvolvimento de um bom trabalho, e sim a sensibilização para a inclusão.

Já a formação continuada foi considerada importante para o desenvolvimento dos trabalhos nesta área nas redes pesquisadas e distintas estratégias foram observadas para o seu desenvolvimento. A mais expressiva é a que faz parte do Programa "Educação Inclusiva: direito a diversidade", do Ministério da Educação. ${ }^{8}$ Quatro dos municípios em tela são considerados cidades-polo desse programa, ou seja, esses municípios recebem formação para repassar a outros municípios da região a qual pertence. Os temas mais recorrentes nessas formações foram Braille, Sorobã, Libras, comunicação alternativa, entre outros. A coordenadora de um dos municípios denominou tal formação de "instrumental". 
Além dessa formação, três municípios contam com o desenvolvimento do projeto intitulado "Educar na Diversidade". ${ }^{9}$ Esta ocorre por meio de tutoria - um profissional é formado pela SEESP e este forma os professores que irão, ou já estão, atuando nas salas de recursos multifuncionais -. Dos municípios analisados, aqueles que tiveram os projetos de implementação das salas de recursos multifuncionais aprovados vem recebendo formação. Em três dos municípios envolvidos neste projeto, a formação ocorre com a utilização dos materiais didáticos oferecidos pela SEESP e ocorrem no contraturno de trabalho dos professores.

Tanto na formação oferecida pelo Programa quanto a do projeto há centralidade no debate sobre recursos e técnicas específicas relacionados à deficiência e observa-se a ausência de discussões referentes a processos escolares.

Outra estratégia presente em seis dos sete municípios pesquisados para formação de seus professores que atuam na rede regular (professores regentes de classe) são os cursos oferecidos pelos profissionais que coordenam os setores específicos para o atendimento dos alunos com deficiência nos municípios e por aqueles que desenvolvem as atividades dos serviços especializados. Na maioria das vezes, essa formação ocorre de maneira assistemática nos municípios, ou seja, tal formação ocorre somente quando há solicitação dos professores regentes e dentro das possibilidades de organização de cada rede.

Quando questionados sobre os temas discutidos na formação dos professores regentes, os mais citados foram a inclusão de uma maneira genérica e as técnicas e recursos. Desse modo, podemos considerar, primeiramente, que a formação continuada está sendo a estratégia mais utilizada para formar os professores que atuam diretamente com os alunos da Educação Especial. A formação inicial ganha destaque quando atrelada a outros critérios considerados essenciais para um bom desenvolvimento dos trabalhos (principalmente a sensibilidade e a abertura para novas experiências).

Com tais elementos, podemos considerar que a formação de professores que trabalham com alunos considerados com deficiência (especialistas ou não) está centrada na formação continuada. Tanto essa como a formação inicial não têm como foco central a articulação entre o AEE e a classe comum. Há, ainda, uma preponderância nas formações de um modelo que secundariza o pedagógico e privilegia o médico-psicológico. Tal encaminhamento pode sinalizar que a proposta de inclusão em curso no país não pressupõe a apropriação do conhecimento escolar por parte dos alunos com deficiência.

\section{Referências}

BOROWSKY, F. Fundamentos teóricos do curso de aperfeiçoamento de
professores para o Atendimento Educacional Especializado (2007): novos 
referenciais? 2010, 140f. Dissertação (Mestrado em Educação)-Universidade Federal de Santa Catarina, Florianópolis, 2010.

BUENO, J. G. S. As políticas de inclusão escolar: uma prerrogativa da educação especial? In: BUENO, J. G. S; MENDES, G. M. L.;SANTOS, R. A.dos. (Org.). Deficiência e escolarização: novas perspectivas de análise. Araraquara, São Paulo: Junqueira \& Marin: Brasília, DF: CAPES, 2008, p. 43-63.

BUENO, J. G. S. A Educação Especial nas universidades brasileiras. Brasília: MEC/SEESP, 2002. 136p.

BRASIL. Conselho Nacional de Educação. Câmara de Educação Básica. Resolução n. 2, de 11 de setembro de 2001. Diretrizes Nacionais para a Educação Especial na Educação Básica. Brasília, 2001.

BRASIL. Conselho Nacional de Educação. Resolução n. 1, de 15 de maio de 2006, que institui as Diretrizes Curriculares Nacionais para o Curso de Pedagogia - Licenciatura. Brasília, 2006.

BRASIL. Instituto Brasileiro de Geografia e Estatística. Brasília. Censo Escolar 2006. Brasília, 2006.

BRASIL. Ministério da Educação. Conselho Nacional de Educação. Câmara de Educação Básica. Resolução n. 4, de 2 de outubro de 2009. Institui Diretrizes Operacionais para o Atendimento Educacional Especializado na Educação Básica, modalidade Educação Especial. Brasília, 2009.

BRASIL. Ministério da Educação e do Desporto. Instituto Nacional de Estudos e pesquisas Educacionais. Lei n. 9394, de 20 de dezembro de 1996. Estabelece as diretrizes da educação nacional, 1996.

BRASIL. Secretaria de Educação Especial. Política Nacional de Educação Especial na Perspectiva da Educação Inclusiva. Brasília. Documento elaborado pelo Grupo de Trabalho nomeado pela Portaria n. 555/2007, prorrogada pela Portaria n. 948/2007, entregue ao Ministro da Educação em 07 de janeiro de 2008.

CARTOLANO, M. T. P. Formação de professores no Curso de Pedagogia: a Educação Especial. Cadernos CEDES, Campinas, SP, ano XIX, n. 46, p.29-40, set. 1998.

CASTEL, R. As armadilhas da exclusão. In: CASTEL, R.; WANDERLEY, L. E. W.; BELFIORE-WANDERLEY, M. Desigualdade e questão social. São Paulo: EDUC, 2000. p. 17-50.

CORREIA, J. R. A construção político-cognitiva da exclusão social no campo educativo. Porto/PT: Universidade do Porto. Mimeo, 2004. 33p.

EVANGELISTA, O. Almas em disputa: reconversão do docente pela ressignificação da educação. 2006. Projeto de Pesquisa. Disponível em <http:/ /www.gepeto.ced.ufsc.br/projetos.php>. Acesso em: 09 jun. 2009. 
EVANGELISTA, O.; TRICHES, J. Reconversão, alargamento do trabalho docente e Curso de Pedagogia no Brasil. In: SEMINÁRIO REDESTRADO "NUEVAS REGULACIONES EN AMÉRICA LATINA, 7.,Buenos Aires, 3 a 4 de julio de 2008. Anais... Buenos Aires: CLACSO; AGENCIA, 2008. p. 1-19.

FRIGOTTO, G. Educação para a "inclusão" e a "empregabilidade": promessas que obscurecem a realidade. In: CANÁRIO, R.; RUMMERT, S.M. (Org). Mundos do trabalho e aprendizagem. Educa. Formação: Lisboa, 2009. p. 61-77.

FREITAS. L. C. de. A internalização da exclusão. In. Educação \& Sociedade, Campinas, v. 23, n. 80, p. 299-325, 2002.

FREITAS, L. C. de; SORDI, M. R. L. de; FREITAS, H. C. L. de; MALAVAZI, M. M. S. Dialética da inclusão e da exclusão: por uma qualidade negociada e emancipadora nas escolas. In: GERALDI, C.M.G.; RIOLFI, C.R.; GARCIA, M. F. (Org.). Escola viva: elementos para a construção de uma educação de qualidade social. Campinas, SP: Mercado das Letras, 2004. p. 61-88.

GARCIA, R.M.C. Políticas inclusivas na educação: do global ao local. In: BAPTISTA, C.R.; CAIADO, K.R.M.; JESUS, D.M. de. (Org.). Educação especial: diálogo e pluralidade. Porto Alegre: Mediação. 2008. p. 11-23.

LEHER, R. Educação no capitalismo dependente ou exclusão educacional? In: MENDONÇA, S.G. de L.; SILVA, V.P. da; MILLER, S. (Org.). Marx, Gramsci e Vigotski: aproximações. Araraquara, SP: Junqueira\&Marin; Marilia,SP: Cultura Academica, 2009. p. 223-251.

MELETTI, S.M.F.; BUENO. J.G.S. Escolarização de alunos com deficiência: uma análise dos indicadores sociais no Brasil (1997-2006). In: REUNIÃO ANUAL DA ANPED, XXXIII, 2010, Caxambu. Anais ... Caxambu: ANPED, 2010. p. 1-17.

MICHELS, M.H. A formação de professores de educação especial na UFSC (1998-2001): ambigüidades estruturais e a reiteração do modelo médico-psicológico. 2004, 170 p. Tese (Doutorado em Educação: história, política, sociedade)-Pontifícia Universidade Católica de São Paulo, São Paulo, 2004.

NUNES, L. R. D. de P. et al. A pós-graduação em Educação Especial no Brasil: análise crítica da produção discente. Revista Brasileira de Educação Especial, Piracicaba, v. 3, n. 5, p. 113-126, 1999.

OZGA, J. Investigação sobre políticas educacionais: terreno de contestações. Porto: Porto, 2000.

SAVIANI, D. Pedagogia: o espaço da educação na universidade. Caderno de Pesquisa, São Paulo, v. 37, n. 130, p.99-134, jan./abr. 2007.

SOARES, M. A. L. A educação do surdo no Brasil. Campinas: Autores Associados; Bragança Paulista: Edusf, 1999.

TRICHES, J. Organizações multilaterais e curso de pedagogia: a construção de um consenso em torno da formação de professores. 2010. 218 p. Dis- 
sertação (Mestrado em Educação)-Universidade Federal de Santa Catarina, Florianópolis, 2010.

VIEIRA, S. R. Diretrizes curriculares para o curso de pedagogia: pedagogo, docente ou professor? 2007, 151 p. Dissertação (Mestrado em Educação)-Universidade Federal de Santa Catarina, Florianópolis, 2007.

UNESCO. Coordenadoria Nacional para a Integração da Pessoa Portadora de Deficiência. Declaração de Salamanca e Linha de ação sobre necessidades educativas especiais. Brasília, 1994.

Site pesquisado: www.mec.gov.br

Notas

${ }_{1}^{1}$ Censo escolar (Brasil, 2006). Sobre os dados estatísticos, ver Meletti e Bueno (2010).

2 A este respeito são muito elucidativas as produções de Evangelista (2006 e 2008), Triches (2010) e Vieira (2007).

${ }^{3}$ Sobre este assunto, ver Bueno (2002).

4 Resolução n. 4 do Conselho Nacional de Educação.

5 Sobre a permanência de ambiguidades na formação de professores, ver Michels (2004).

6 Ver, entre outros, Nunes et al. (1999), Soares (1999) e Michels (2004).

7 Em dois municípios, foram observadas a presença de uma professora de Educação Física e uma comerciante (sem formação específica) como organizadoras do setor.

8 Segundo a SEESP, o objetivo desse programa é difundir a "política de educação inclusiva nos municípios brasileiros e apoiar a formação de gestores e educadores para efetivar a transformação dos sistemas educacionais em sistemas educacionais inclusivos" (www.mec.gov.br, acesso em: 16 jan. 2008.

9 Este projeto é o resultado do Projeto "Educar na Diversidade nos Países do MERCOSUL", desenvolvido na Argentina, Brasil, Chile, Paraguai e Uruguai, entre 2000 e 2003. Contou com financiamento da Organização dos Estados Americanos (OEA) e com assessoria técnica da UNESCO. (www.mec.gov.br. Acesso em: 16 jan. 2008).

\section{Correspondência}

Maria Helena Michels - Campus Universitário Reitor David Ferreira Lima. Trindade, CEP: 88010-970 - Florianópolis, Santa Catarina, Brasil.

E-mail:mhmichels@uol.com.br

Recebido em 15 de março de 2011

Aprovado em 27 de maio de 2011 